Article

\title{
Laboratory Experiments of Tradable Development Rights: A Synthesis of Different Treatments
}

\author{
Till Proeger *, Lukas Meub and Kilian Bizer \\ Chair of Economic Policy and SME Research, University of Goettingen, 37073 Goettingen, Germany; \\ lukas.meub@wiwi.uni-goettingen.de (L.M.); bizer@wiwi.uni-goettingen.de (K.B.) \\ * Correspondence: Till.Proeger@wiwi.uni-goettingen.de; Tel.: +49-551-39-4626
}

Received: 26 April 2018; Accepted: 16 May 2018; Published: 12 June 2018

check for updates

\begin{abstract}
Tradable development rights (TDR) are considered by scholars and regulators in various countries as a means of reducing land consumption efficiently. Similar to the development of $\mathrm{CO}_{2}$-certificate trading schemes, the methodology of experimental economics can be used to derive empirical evidence on the core parameters and problems of TDR schemes, thus extending theoretical modelling and evidence from case studies. Building on a common laboratory experimental framework, we discuss results from five distinct experiments that consider mechanisms of allocation, resilience against external shocks, political business cycles, communication and collusion, and risk. These results provide initial empirical directions for the further study and introduction of TDR schemes for managing and reducing environmental issues related to land consumption for building projects.
\end{abstract}

Keywords: cap \& trade; economic experiment; land consumption; land use; tradable planning rights

\section{Introduction}

Policy makers in various countries aim to substantially reduce land consumption and its related cost in ecological and fiscal terms. In this discussion on how to achieve a more sustainable level of land consumption, the introduction of a cap and trade system using tradable development rights (TDR) has been suggested by scholars and policy-makers alike. Based on its inherent flexibility of having market forces determine which projects are sufficiently valuable to justify land consumption-while strictly adhering to the predefined cap on the aggregate level—a cap and trade system is assumed to be an instrument superior in efficiency to traditional regulatory measures (see e.g., [1-5]).

Previous studies on TDR schemes have conducted surveys of case studies, mostly for the United States (e.g., [6-12]). The TDR schemes described and evaluated are, however, often highly context and country dependent and their respective policy implications might therefore lack generalizability. We thus suggest that laboratory experimental studies can be used to complement this prior empirical research and add context-independent, and, therefore, more generalizable results. We present an experimental approach allowing us to abstract from contextual influences and country specifics in order to gain insight on the fundamental behavioral patterns at play in TDR systems. Further, quite specific factors affecting cap and trade systems such as macroeconomic shocks or political business cycles as well as various potential policy instruments can be investigated [13].

This paper aims to summarize, interrelate, and discuss the findings of a series of experimental studies conducted in recent years by the authors [14-18]. While there are several experiments testing $\mathrm{CO}_{2}$ trading schemes (e.g., $\left.[19,20]\right)$, on which our experimental design builds, there have been only few (field) experimental approaches dealing with TDR (e.g., [21]). We therefore present a novel experimental framework that can be used to test various aspects of TDR in a controlled laboratory setting. 
For various issues of institutional design, there is an ongoing debate on the benefits and issues of using experimental evidence for applied policy-making. A number of authors suggest a pragmatic approach, whereby evidence from behavioral and experimental studies is used as a complement to empirical and theoretical findings (see e.g., [22-25]). Other strands of discussion are more skeptical about the broad applicability of laboratory evidence across contexts (see e.g., [26] for the arguments). While both sides of the discussion have valid arguments, giving practical policy implications requires a pragmatic approach to designing and interpreting experimental results. Following this approach, our experiments are designed to offer complementary evidence to the surveys on TDR schemes. The laboratory settings allow us to derive counterfactual evidence on specific institutional parameters $[27,28]$, in our case within a cap and trade scheme for land consumption. We refer to the papers summarized below [14-18] for a comprehensive discussion of whether and how experimental results are applicable in the context of working mechanisms of TDR scheme.

In brief, we argue that, while theoretical modeling offers perfect internal validity, its external validity for actual TDR schemes with imperfectly rational agents remains disputable. Case studies, by comparison, feature a somewhat higher degree of external validity, while the generalizability of the derived implications similarly remains weak (see e.g., [29] for a more detailed methodological discussion of this aspect). Laboratory studies can serve to better link these two approaches to create an insight into the optimal design of TDR schemes. Laboratory experiments generate empirical evidence in a controlled and internally valid environment, while their external validity might be questioned. Obviously, an experimental set-up cannot capture all specifics of actual TDR markets. Nonetheless, valuable evidence can be obtained, when the set-up incorporates the general working mechanism and relevant specifications. The evidence obtained can then be transferred to enrich the empirical basis and the assessment of theory for the actual design of institutional frameworks. Also, comparing the behavior in a TDR setting of student participants with actual regional planners, leads to the conclusion of quite similar results regarding the efficiency of the cap and trade system [21]. We are therefore confident that our experimental studies add to previous work on TDR both theoretically and empirically.

Experimental approaches to TDR need to capture its core parameters, particularly that cap and trade systems rely on market forces, where flexible prices signal scarcity of TDR. Independent of actual prices, agents' willingness to pay-representing the value of underlying projects-defines the allocation of TDR and, ultimately, determines which land consumption projects are realized. This market based regulatory approach has been prominently discussed and implemented in the context of $\mathrm{CO}_{2}$ emissions, but has also (previously) been transferred to $\mathrm{SO}_{2}$ emissions or to scarce resources such as water [19,30-35].

The market based approach of a cap and trade system for TDR is discussed among economists in many countries. For instance, [36] consider the Australian case; [37], China; [38], Germany; [39] or [7], Italy; [40], the Netherlands; or [41], Switzerland. Most experience with TDR schemes can be found in the United States, where this approach has been implemented on a regional level for several decades (for an overview, see [42]). For the case of Germany, the national sustainable development strategy [43] defines the objective of a substantial reduction in land consumption, which has been confirmed later on, for example by the coalition treaty of the 2013 administration. The reduction aims to restrict land consumption to a maximum amount of 30 ha per day [44]. Contrastingly, land consumption amounted to about 74 ha per day in Germany in the years 2009 to 2012 [45]. Intertwined with the regulatory discussion, scientific research has developed, identifying institutional, administrational, and judicial constraints for such a TDR scheme in Germany (for an overview see [46-48]).

It is notable that there are considerable differences in the discussion and implementation of TDR schemes across countries. Ubiquitously, authors justify TDR schemes due to their assumed superiority in efficiency of the market based instrument. However, established systems show regional specifics and deal with heterogeneous objectives and problems regarding land consumption. For instance, in the United States, TDR schemes are often regionally limited in scope and embrace private and public 
agents within one system. Contrastingly, the discussion in Germany revolves around a nation-wide system where the federal government is in power to set the cap and act as the sole issuer of certificates that need to be acquired by local municipalities to realize land consuming projects.

These country specifics have led to a case-study perspective when it comes to empirical research concerned with TDR schemes. Accordingly, the policy implications derived in the studies often tend to be restricted to regional specifics. For instance, [11] identify strong demand for new areas and tailored receiving areas on the regional level as primary factors for the effectiveness of TDR schemes. However, there are meta-studies unifying many case-studies that are quite heterogeneous in nature. These studies rely on qualitative (e.g., [8,11,49-52]) or quantitative measures [41,53-55]. Despite the broader perspective of some studies, we suggest that the evidence remains weak and makes overarching conclusions for TDR schemes difficult due to the regional or even local focus of the underlying case studies. To provide complementary empirical evidence adding to theoretical and case-study based results, we suggest that laboratory experiments should be used as a meaningful new source of insight on the working mechanisms of TDR schemes.

We therefore present a universal design that captures the fundamental characteristics of a TDR scheme, while abstracting from regulatory and country specifics. This design allows the application and transfer of our framework to manifold contexts. Further, building on a straightforward model of payoff-maximizing behavior, we are able to look into distinct policy measures by using treatment manipulation. In our game, subjects represent agents within a TDR market for multiple periods. These roles of the experimental subjects in the game do not change. Agents are assigned different characteristics in terms of available land consumption projects and TDR grandfathered, which simulates differences in size and land value in market participants. Overall, agents need to realize land development projects to generate income. There are three stages in each period of the game. In the first stage, TDR certificates are either auction or grandfathered. In the second stage, the certificates can be traded on a double auction market. In the third stage, certificates can be used to realize land consumption projects. If subjects lack certificates, they are still able to realize (by far) less profitable default projects representing inner-city development. Income from project realizations and net income from certificate trading are added up and paid to participants after the game. Our experiments contain no framing, thus there are no explanations regarding land use, environmental issues, or building projects. Also, the land consumption simulated in our experiments does not differentiate between specific areas, such as agricultural, rural, or urban regions.

For our analysis, we compare treatments by accumulated welfare within a TDR market. Welfare is determined by the aggregate values of realized projects, which, in turn, are determined by the allocation of certificates. If projects are allocated efficiently, thus allowing the realization of the most valuable projects, aggregate welfare is maximal and the system works efficiently. Trading on the secondary market redistributes income among players and thus only affects income on an individual level. However, certificate price developments and income distribution within and across treatments are important indicators to evaluate the cap and trade scheme as they crucially influence the acceptance and feasibility on a political level.

Based on these design choices, we conduct five experimental studies with a total of 492 participants. First, we study the effects of different modes of certificate allocation. Substantially different results arise, conditional on whether certificates are grandfathered or auctioned, which contradicts theoretical predictions. Auction prices tend to be excessively high leading to a considerable transfer of income in favor of the auctioneer. Second, we introduce exogenous shocks affecting agent budgets or project revenues. The cap and trade systems proves to be resilient as these shocks are absorbed without any strong distortions regarding overall efficiency. Third, we implement the fact that agents in TDR schemes are often public entities, who follow non-payoff-maximizing incentives such as maximizing their likelihood of being reelected. We find these incentives to interfere with the efficient allocation of certificates and, accordingly, overall welfare. Price volatility and income heterogeneity tend to increase considerably as a consequence. Fourth, we implement project revenues that are risky and potentially negative. We find 
distortions in terms of efficiency as risk preferences instead of the expected project revenues become dominant in determining the willingness to pay for certificates, ultimately shifting certificate allocation away from the optimum. Fifth, we investigate potentially collusive behavior among market participants and the effects of mandatory cooperative decision-making. Cooperative decision-making tends to increase the efficiency of the cap and trade system as cognitive limitations and biases are reduced substantially. There is no welfare damaging collusive behavior.

Apart from these treatment effects, we can identify general results offering a valuable insight for the design of cap and trade systems for TDR. Auction prices are persistently exceeding secondary market prices, which cannot be explained theoretically. We suggest the endowment effect as a plausible explanation of this finding, pointing to the overreaching relevance of biases and heuristics in decision-making affecting the outcomes of cap and trade systems. Further, prices in auctions and secondary markets tend to overshoot fair values within the first couple of periods, while they decrease over the course of the game and tend to be lower than fair values in the end of the game. These price dynamics can be explained by strong learning effects of market participants, implying the need for comprehensive information and extensive training when introducing cap and trade systems. Overall, the system proves quite robust and capable of absorbing external distortions, as there were no complete market breakdowns and deviations from optimal certificate allocation remain modest.

In sum, we can draw a number of conclusions that help to understand the dynamics of cap and trade systems. We identify important factors that drive the behavior of market participants that need to be accounted for when aiming to design an optimal cap and trade system. Our results are relevant ex ante when designing a cap and trade system for TDR. Further, ex post, policy makers can rely on our findings to derive measures to improve an established system's outcome.

The remainder of this paper is organized as follows. The second chapter details our experimental approach to derive empirical evidence on the functioning of cap \& trade systems, in particular for the case of TDR. The third chapter presents our experimental findings. Chapter four concludes and discusses policy implications and issues for future research.

\section{Design of Experiments}

Our empirical studies build on a consistent experimental framework. Various treatments are compared to our baseline setting to investigate potential distortions to the cap \& trade system or to study the effects of specific policy measures. The between-subjects design is rather abstract, meaning that our framework applies to manifold contexts and elicits basic findings that show validity independent of, for example, country specifics.

\subsection{Course of the Game}

In our design, subjects need to realize projects to generate income over the course of 15 periods. These projects are of two types representing either (A) land consuming building projects or (B) inner-city development, whereby these and all other connections remain unknown to subjects as there is no framing, that is, there is no mentioning of land conservation or terms alike to subjects (Please find the instructions for our baseline treatment in Appendix A. The instructions are only slightly adjusted to implement the specific conditions of the other treatments.). Inner-city developments are assumed to be less profitable and do not require any certificates to be realized. Land consuming building projects tend to be more profitable and require certificates.

In stage one of the experiments, a primary market is established where certificates are either grandfathered or auctioned (uniform price with sealed bids) by the experimenter representing a public authority. In stage two, subjects simultaneously place bids and offers to trade certificates with other participants on a secondary (double auction) market. The secondary market is open for two minutes each period, while there are no limits to trade volumes and no transaction costs. There is no borrowing, that is, subjects are bound by their budgets (For a screenshot of the secondary market's interface, please refer to the instructions in Appendix A.). In the third stage, certificates can be used to realize 
projects. Subject are allowed to realize one project per period. Figure 1 depicts the general experimental framework by summarizing the three stages of each period (see also [16] for the figure).

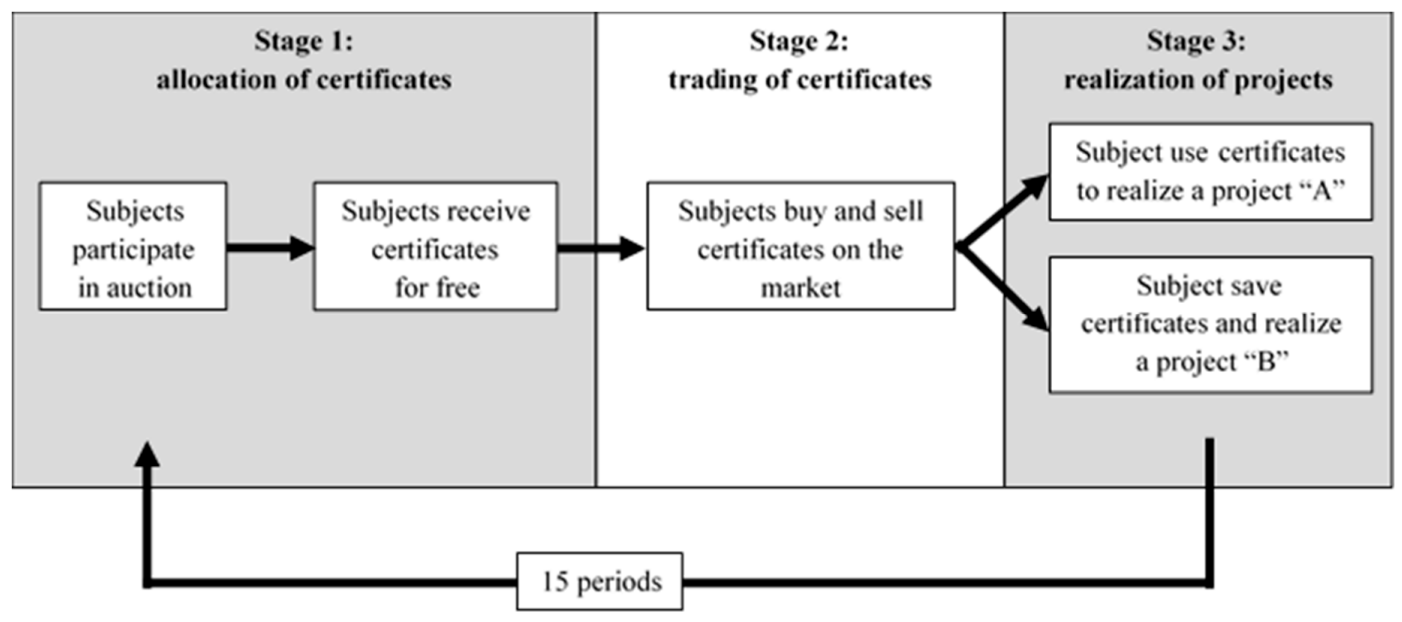

Figure 1. General experimental framework.

\subsection{Certificates}

Certificates are restricted in volume such that only half of market participants are able to conduct land consuming projects. Certificates can be accumulated over periods and become worthless at the end of the game. Given payoff-maximizing behavior, certificates should be strictly allocated in such a way as to enable the realization of the most valuable projects as these projects induce the greatest willingness to pay. This behavior leads to the efficient outcome when aggregate land consumption is restricted. As one of the means to keep the game simple, all projects require an equal number of certificates.

\subsection{Players and Markets}

Subjects are assigned to one of six player types, which are matched to one TDR market. These player types represent municipalities of different size and potential to conduct land consuming projects. Accordingly, the endowment of projects and the number of certificates grandfathered vary over player types, where larger municipalities receive more certificates and more valuable projects. Subjects learn about the distribution of project values, but remain uninformed about the specific endowment of other players' projects. However, to keep the game comprehensible for subjects, the initial budgets assigned are equal across player types and set to allow for certificate prices to reach fair values. A restricted budget for some players would decrease certificate prices and imply that willingness to pay would vary over player types, independent of available projects. Given our design choice, subjects are (in theory) able to derive all other players' maximum willingness to pay for certificates, which is given by the surplus of conducting the most valuable land consuming projects compared to the default option of inner-city development divided by the number of certificates required. For instance, our most valuable land consuming project pays $100 \mathrm{ECU}$ and the default project of inner-city development pays $10 \mathrm{ECU}$. Since eight certificates are required to realize the land consuming project, the fair price for one certificate is given by $11.25 \mathrm{ECU}[=(100-10) / 8]$. We refrain from explaining the theoretical base of our experimental design in this review. For comprehensive descriptions, we refer to either of our papers reviewed below.

\subsection{Payment}

All prices in the experiment are denoted in experimental currency units ECU that convert into Euro by a fixed rate. As mentioned above, subjects generate income by realizing projects. Revenues for realized projects, however, are withheld until the end of the game, which represents the long-term 
character of most development projects and keeps the game simple without loss of generality. Further, subjects may generate income in the secondary market by trading certificates, where grandfathered certificates are sold off or even speculation motives can be followed. These transactions affect budgets right away. The resulting budgets at the end of the game and the revenues from realized projects are added up, converted to Euro and paid to the participants. Payments depend on player types, treatment assigned and, most importantly, on subjects' behavior within a market. On average over experiments, subjects earned about $€ 15$, where the average duration was about $80 \mathrm{~min}$. However, also payments below $€ 10$ or above $€ 30$ were realized.

\subsection{Procedure}

The experiments were carried out at the Laboratory for Behavioral Economics at the University of Goettingen. They were programmed using z-Tree [56] and participants were recruited through ORSEE [57]. A universal understanding of the game was ensured through prior control questions. Subjects were only allowed to participate once, thus observations across treatments are strictly independent. The instructions for the game were in German; English translations for all experiments can be obtained from the authors upon request. Participants were recruited from various academic disciplines, comprising undergraduate and graduate students. The sample specifics are detailed in each of the separate papers.

\subsection{Overview of Experiments and Participants}

Table 1 gives an overview of the treatments conducted. All experiments rely on our baseline treatment as a benchmark, where half of the certificates are grandfathered and half are auctioned (cp. experiment 1 -modes of allocation). Baseline features neither budgetary cuts nor variations in project values (cp. experiment 2 -resilience against exogenous shocks). There are no reelection motives implemented (cp. experiment 3-political business cycles) and project revenues are deterministic and not risky (cp. experiment 4-uncertainty in project revenues). Further, there is no communication among market participants and decision are taken individually (cp. experiment 5-communication and collusion).

Table 1. Overview of the different treatments and the number of participants.

\begin{tabular}{ccc}
\hline Experiment & Treatment & No. of Participants \\
\hline All & Baseline & 48 \\
\hline \multirow{2}{*}{ Modes of allocation } & full auction & 42 \\
& full grandfathering & 42 \\
\hline \multirow{2}{*}{ Resilience against exogenous shocks } & reduction in project values & 48 \\
& budgetary cut & 48 \\
\hline \multirow{2}{*}{ Political business cycles } & weak reelection motive & 48 \\
& strong reelection motive & 48 \\
\hline \multirow{2}{*}{ Uncertainty in project revenues } & low risk in project revenue & 48 \\
& high risk in project revenue & 48 \\
\hline \multirow{2}{*}{ Communication and Collusion } & interaction of market participants & 48 \\
& team decision-making & 24 \\
\hline Total & & 492 \\
\hline
\end{tabular}

\section{Summary}

\subsection{Modes of Allocation (The Respective Paper Is Published as Follows: [14])}

\subsubsection{Motivation and Research Question}

One of the basic research questions to be considered prior to the implementation of TDR-schemes is the optimal mode for the initial allocation of certificates. While efficiency is assumed to be 
independent of the initial endowment, the political feasibility might crucially depend on the mode of allocation. A politically influential issuing entity will push for auctioning certificates as it guarantees additional income for the auctioneer and lower payments between market participants. By contrast, politically influential market agents-especially those with weak land consumption projects available-will favor grandfathering of certificates as they receive compensation payments for not conducting building projects. Further, agents constrained by low budgets remain capable of conducting projects by saving up certificates. Since the political feasibility ultimately determines the relevance of this instrument, empirical investigations of the various institutional alternatives are imperative.

From a purely theoretical perspective, the mode of initial allocation has no efficiency effects and merely implies different final distribution of rents, the extent of which can be determined ex ante; this, however, implies optimal behavior by all agents involved with a TDR scheme. Given that government officials running the system, local authorities, and private agents using the certificates for building projects in practice may not show such fully payoff-maximizing behavior and will necessarily have incomplete information, empirical testing of the allocative mode can yield important insight into a TDR-scheme's functioning.

We therefore use our basic experimental design and test three different modes of initial allocation with respect to effects on overall efficiency, income distribution, price dynamics and the occurrence of behavioral anomalies different from theoretical predictions.

\subsubsection{Experimental Treatments}

Treatments only differ in terms of the mode regarding the initial allocation of certificates.

- Treatment 1 implements a 100\% auctioning of certificates, meaning that any certificates to be used for building projects are costly and need to be acquired through the auction at the beginning of each period.

- Treatment 2 implements a 50\% auctioning and a 50\% grandfathering of certificates. Thus, even agents with a weak initial endowment in terms of building projects receive a certain amount of certificates.

- Treatment 3 implements a full grandfathering of certificates with no auctioning at all. Therefore, the number of certificates received each period solely depends on player types.

Overall, we consider the two possible extreme-scenarios for a TDR-scheme, namely full auctioning (favored by issuing and regulating entities) and full grandfathering (favored by agents affected by the TDR scheme) as well as a middle-approach, which could provide a middle ground from both perspectives.

\subsubsection{Results}

Although equivalent from a theoretical perspective, the modes of allocation yield substantially different results in our experiment. While full auctioning has income distribution to be less dependent on player type (size of the agent), it also leads to lower efficiency and a higher instability of the system due to higher price volatility. Also, increased variance in aggregated welfare within and across markets hint at greater instability. For auctioning treatments, price exaggerations at the beginning of the game have a strong income effect in favor of the auctioning entity, which is likely to reduce the political acceptance of the system. Moreover, there are persistently higher prices in the secondary market compared to prices in the initial auctions for all treatments, meaning that there might be an endowment effect at play, which again is a source of inefficiency and misallocation. While it remains unclear whether or not actual market participants suffer similarly from endowment effects in TDR schemes, this bias has been shown to be an extraordinarily robust behavioral anomaly and therefore might diminish the system's efficiency substantially. If this holds true, a TDR scheme relying on auctioning would be inferior in transferring certificates to the most valuable land consuming projects, 
thus reducing the advantage in terms of efficiency for a market based cap and trade system. Besides our evidence on substantially reduced efficiency and stability of the cap and trade system when auctioning certificates, the important issue of budget constraints for market participants is not implemented in our design. This provides an additional argument that grandfathering is likely to be superior to auctioning certificates.

\subsection{Resilience against Exogenous Shocks (This Study Has Been Published as: [16])}

\subsubsection{Motivation and Research Question}

A potential weakness of market based TDR schemes might lie in its reaction to exogenous shocks, for example those caused by macroeconomic instability. Those shocks might affect prices and the allocation of TDR, which could ultimately distort the system's efficiency. Again, from a theoretical perspective, reactions to exogenous shocks can be predicted by suitable modeling. However, the modeling approach overlooks the behavioral reactions to substantial changes of core parameters in a market system, which might be quite "irrational". Relying on our experimental framework, we provide empirical evidence on individual and collective reactions to exogenous shocks in a TDR cap and trade market as a means of informing regulators of potential behavioral distortions. We therefore test the effects of two shocks and assess individual and overall market reactions in terms of overall efficiency, price dynamics, and income distribution.

\subsubsection{Experimental Treatments}

There are three treatments altogether, which implement two different shocks and no shock at all.

- Treatment 1 (henceforth denoted "baseline" features no shock. It is identical with the second treatment of our first experiment.

- Treatment 2 features a sudden reduction of project revenues during the game, of which experimental subjects are not informed in detail prior to the game. Therefore, the relative value of all projects changes, forcing subjects to adjust their pricing.

- Treatment 3 implements a sudden budgetary cut, meaning that subjects at some point lose their ability to finance certificates to realize projects, again resulting in pressure towards adjusting market behavior.

Overall, the shock treatments simulate the effects of regional or national downturns in economic activity, resulting in loss of value to building projects or budget cuts due to loss in taxes. These realistic scenarios might crucially alter the efficiency and political feasibility of a cap and trade system for land consumption. Insights from our experiment aim to offer evidence to support an informed policy design.

\subsubsection{Results}

Overall, we find that the reaction towards the exogenous shocks is fairly efficient and close to theoretical predictions. Therefore, the system does prove resilient against substantial exogenous shocks as simulated in our treatments. Similar to our other experiments, we find bidding prices in auctions to be higher than market prices. This leads to a redistributional effect in favor of the auctioneer exceeding theoretical predictions. Nevertheless, in terms of overall efficiency and welfare, the TDR scheme proves largely optimal and stable. In the aftermath of the shocks, there is a slight increase in price volatility both in auctions and in the secondary markets and an ensuing increase in income heterogeneity. However, trading volumes are largely unaffected and price volatilities peter out over the course of the game. From a policy perspective, the TDR scheme (as implemented in our experiment) can be considered quite resilient against macroeconomic shocks. This provides a strong argument in favor of this market based instrument, since the system additionally offers higher flexibility than static regulations on land consumption following economic shocks. 


\subsection{Political Business Cycles (This Study Has Been Published as [15])}

\subsubsection{Motivation and Research Question}

Another common issue when discussing the introduction of TDR schemes from a policy perspective is the assumption that agents will decide in payoff-maximizing manner considering costs and benefits, meaning that they will only buy certificates if their price is equal to or below the value satisfied by underlying building projects. However, given that TDR schemes will likely be influenced by national or regional politics as market participants are political entities, it should be assumed that alternative motivations will play a substantial role in determining individual decisions. If this holds true, the argument of superiority in efficiency fails as certificates will no longer be allocated by the market system toward the most valuable building projects. Motivations might be related to reputation effects for local politicians deciding on and inaugurating new building projects. We test the behavioral effects of two different reputational incentives that rely closely on those faced by real-world municipal decision-makers that strive for reelection. First, realizing a certain number of building projects as a means of showing a high level of activity. Second, accomplishing a highly prestigious (and costly in terms of certificates) building project to signal strong capability and competence. We assume simultaneous election periods for market participants, that is, reputation incentives become evident for all agents in the same period at about half way through the game. Again, we determine the effects of the treatment manipulations on individual and collective behavior, efficiency, price dynamics and income distribution. Particularly, we are interested in distortions prior and in the aftermath of an election period.

\subsubsection{Experimental Treatments}

There are three treatments, in which the two political reputation incentives can be compared to our baseline treatment.

- Treatment 1 again is given by our baseline, featuring no reputational incentives.

- $\quad$ Treatment 2 introduces a single prestigious project, meaning that the realization of a certain project during the game yields a substantial bonus payment, simulating the increase in a politician's likelihood to be reelected. This prestigious project, however, requires certificates, leading to a situation of excess demand for certificates, if all agents try to acquire the bonus payment at the same time. However, this treatment implements a rather weak political business cycle, since there are enough certificates so that all agents can achieve the bonus simultaneously if they had saved up enough certificates.

- Treatment 3 implements a more substantial manipulation, simulating incentives to increase reelection probability by realizing a certain number of projects. Again, this leads to a situation of increased competition for the limited certificates. In this treatment, there are not enough certificates for all agents to achieve the bonus payment simultaneously.

Overall, this setting enables us to estimate the behavioral effects of reputation incentives as they would likely occur before elections within a TDR scheme.

\subsubsection{Results}

Overall, we find substantial distortions due to reputational incentives. There is an increased volatility of auction and secondary market prices concurring with the endowment effect described above. Heterogeneity of income is increased and the distribution of realized building projects is rendered non-optimal. Consequently, the market system prerequisite for superiority in terms of efficiency fails. This is due to subjects striving for the bonus payment by buying certificates and conducting building projects almost regardless of their inherent value. While this might be optimal behavior regarding the maximization of individual income, from an aggregate society level it is welfare damaging. Further, a strategic hoarding of certificates and postponement of building projects 
occurs, which is likely to be an unintended side-effect. Overall, reputational incentives can have strong distortive effects prior and in the aftermath of election periods, which reduces a cap and trade system's political feasibility and requires distinct institutional settings to prevent those effects.

\subsection{Uncertainty in Project Revenues (Published as: [18])}

\subsubsection{Motivation and Research Question}

We investigate the issue of uncertainty connected to the acquisition, trading and usage of TDR. Since decision-making associated with land-use necessarily covers a substantial time-span and involves numerous different agents with varying incentives, it is inherently difficult to estimate the value of building projects and decide optimally according to that information. Therefore, it is relevant to test how subjects react when confronted with uncertainty within a TDR framework. Potential detrimental effects on a cap and trade system's efficiency stems from certificates being allocated according to risk preferences rather than project values. If uncertainty were to distort efficiency and welfare, it would considerably reduce its political and economic attractiveness since uncertainty in land use decisions cannot be ruled out. Using our established experimental framework, we implement the aspect of uncertainty by rendering project revenues risky where we introduce a modest and a more substantial manipulation. As before, we assess the individual and overall effects of this treatment manipulation.

\subsubsection{Experimental Treatments}

To assess the effects of uncertainty on individual decision-making in a TDR framework, we introduce two treatments to be compared to baseline. In the treatment conditions, projects no longer feature a unique and fixed value associated with a certain payment after the game, but rather a distribution of three potential values. However, expected values remain unchanged when compared to our baseline. Subjects learn about the realizations of actual project profitability not until after the game.

- $\quad$ Treatment 1 is again given by our baseline, featuring non-risky project revenues.

- Treatment 2 implements a low risk condition, meaning that the risk associated with project revenues is fairly low and profitability cannot become negative. For instance, for a project worth $100 \mathrm{ECU}$ in baseline, this manipulation introduces a value of $50 \mathrm{ECU}, 100 \mathrm{ECU}$, or $150 \mathrm{ECU}$ all with a one in three chance.

- Treatment 3 implements a higher risk condition. For instance, for a project worth $100 \mathrm{ECU}$ in baseline, this manipulation introduces potential values of -100 ECU, $100 \mathrm{ECU}$, or $300 \mathrm{ECU}$ all with a one in three chance.

Once again, calculating treatment differences enables us to assess the effects of risky project revenues within a cap and trade system on prices, welfare, and income distribution.

\subsubsection{Results}

This experimental approach to risk and TDR schemes, yields distinct behavioral patterns connected to increased risk in project revenues. Primarily, higher levels of risk lead to reduced auction prices, which in turn reduces the transfer payments from agents to the auctioneer. This hints at dominant risk aversion among market participants. Another result is the persistence of diverging primary and secondary market prices for all treatment conditions, which we ascribe again to the endowment effect. Finally, we find that individual risk preferences impact the specific distribution of project realizations. Risk-loving or risk-neutral subjects, who are less concerned with increased income volatility buy more certificates from risk-averse players regardless of player types and underlying project revenues. Consequently, there is a distortion in the efficient distribution of project realizations, since it is not those players with more valuable projects that tend to realize projects, but those that are less risk-averse. On an aggregate level, this effect leads to a reduction of overall welfare in conditions of higher risk. However, this effect is only evident for the stronger risk 
manipulation. From those results, we draw the conclusion that TDR schemes prove to be an effective mechanism for conditions of low risk in project revenues, but that higher volatility in project revenues can easily distort the system's efficiency. This is not to say that specific regulations of the cap and trade market could not cope with these issues; however, they need to be recognized prior to the introduction of TDR schemes in contexts with potentially volatile profitability of the respective land use projects.

\subsection{Communication and Collusion (Published as: [17])}

\subsubsection{Motivation and Research Question}

Finally, we conducted a study to determine the effects on the effectiveness of a TDR scheme regarding different modes of communication within entities representing market participants and between market participants. We assume that it is likely that agents within a TDR scheme will communicate and thus establish cooperative or even collusive structures. For instance, municipal agents who would use a TDR system in Germany, are members in numerous inter-municipal exchange forums, in which political and regulatory issues are discussed and coordination is established. Since TDR schemes-and cap and trade systems in general-assume that its agents act autonomously and strive to maximize individual payoffs, coordinative structures and non-market agreements might distort the system's efficiency and run counter to its theoretical predictions, for example, by lowering biddings in auctions based on collusive action. Therefore, since communication and cooperation is likely to be a constant feature of real-world TDR schemes, we run two different treatments to provide initial evidence as to whether agents establish cooperation and therefore systematically alter the system's results compared to a situation without systematic communication. Cooperation might result in collusion against the auctioneer or in generally lower prices in primary and secondary markets due to agreements among participants. In turn, loosening the assumption of individual decision-making of agents and introducing cooperative decision-making based on communication, might help to overcome cognitive limitations and allow for more sophisticated strategies.

\subsubsection{Experimental Treatments}

We conduct two treatments with different modes of communication to assess the behavioral reactions to this different institutional setup and compare them to baseline.

- $\quad$ Treatment 1 refers to the baseline as before, featuring no communication at all.

- Treatment 2 implements a chat box by which all market participants can send and receive messages during the game. This provides an efficient means of communication, thus enabling collusion and cooperation.

- $\quad$ Treatment 3 implements a random matching procedure among participants, which builds teams of two subjects acting as a single agent during the game. Teams are seated at a single computer; therefore, they communicate face-to-face when finding game strategies.

We thus simulate communication in a broader network of agents and intra-agent cooperation.

\subsubsection{Results}

Overall, we find that the communication within 2-person teams reduces both primary and secondary auction prices, taking prices closer to theoretical values. Therefore, the distributional effect in favor of auctioneers shown in the previous studies is substantially reduced, which increases the system's political feasibility when assuming that teamwork by agents within public entities is common. The cap and trade system's overall efficiency thus improves substantially when introducing team decision-making. Turning to chat communication among market participants, we find no similar improvement in efficiency. However, auction prices are also lower when compared to the baseline, which is a similar effect when compared to team decision-making and thus does not necessarily imply collusive behavior. Analyzing communication patterns, we then find no evidence of direct collusive 
behavior among participants, that is, there are no direct price arrangements among participants. Rather, individual subjects tend to reveal relevant information about the working mechanisms of the system to all other participants, enabling them to make more accurate calculations regarding fair certificate prices. Thus, the overall understanding of the game improves due to communication, which leads to primary and secondary market prices converging towards theoretical values. This effect is evident for both communication modes. The disclosure of additional information makes the system more stable and theoretically predictable. Assuming that communication among agents running real-world TDR systems will be a common feature, our results increase its political feasibility and support its superiority in terms of efficiency.

\section{Conclusions and Policy Implications}

We conclude this brief survey of our five experimental studies on TDR schemes by presenting the core results in Table 2 and by discussing the resulting policy implications.

Table 2. Overview of results.

\begin{tabular}{|c|c|}
\hline & Core Results \\
\hline \multirow{6}{*}{ General results } & Persistently high auction prices favor the auctioneer \\
\hline & Likely endowment effect once certificates have been acquired \\
\hline & Consistently high trading volumes on secondary markets \\
\hline & Prices converge towards theoretical values over the course of the game \\
\hline & Substantial learning effects throughout the game \\
\hline & Fairly strong stability of the overall system \\
\hline \multirow{4}{*}{ Modes of allocation } & Auctions prove problematic due to excessively high prices \\
\hline & Income redistribution favors the auctioneer \\
\hline & This effect is likely to reduce the political feasibility of auctions \\
\hline & Grandfathering induces both more accurate pricing and increased overall welfare \\
\hline \multirow{4}{*}{$\begin{array}{l}\text { Resilience against exogenous } \\
\text { shocks }\end{array}$} & Prices adjust quite efficiently to shocks \\
\hline & Slight volatility increases lead to minor income redistribution \\
\hline & $\begin{array}{l}\text { Trading volumes are unaffected, increased volatility decreases quickly in } \\
\text { the aftermath of the shock }\end{array}$ \\
\hline & TDR scheme proves rather resilient against shocks \\
\hline \multirow{3}{*}{ Political business cycles } & Reputational incentives have a strong impact on behavior \\
\hline & Overshooting prices prior to elections and volatility in prices result \\
\hline & Overall efficiency and welfare suffer as a consequence \\
\hline \multirow{5}{*}{ Uncertainty in project revenues } & Higher degrees of risk in project revenues reduce auction prices \\
\hline & This decreases redistributional effects towards auctioneer \\
\hline & Risk distorts certificate-allocation according to risk-preferences \\
\hline & Lower-value projects are realized by less risk-averse players \\
\hline & Consequently, overall welfare is reduced \\
\hline \multirow{4}{*}{ Communication and collusion } & $\begin{array}{l}\text { Communication shifts primary and secondary market prices closer to theoretical } \\
\text { values }\end{array}$ \\
\hline & No collusion occurs, but information is shared openly \\
\hline & This reduces redistribution towards the auctioneer \\
\hline & Communication improves overall efficiency due to learning effects \\
\hline
\end{tabular}

We suggest that our experimental approach has yielded considerable new empirical findings on the working mechanisms, advantages, and potential issues connected to the introduction of TDR schemes. We argue that—while an experimental approach has natural limitations-it can add important behavioral insights, valuable when designing and implementing real-world institutional 
mechanisms intended to reduce land consumption. We are quite aware that our design specifications and results do not capture each potential TDR design and that laboratory subjects' decisions fail to fully represent municipal decision-making. In particular, it has to be considered that experimental subjects are students and might therefore act fundamentally differently to municipal agents (although the initial results by [21] suggest otherwise). Further, the number of agents in a real-world TDR scheme would substantially increase compared to our sample. While our experiment-for the sake of practical feasibility-features constant projects, real-world developments are by far more flexible and should be assumed to change regularly. Finally, there will be different regulations, spatial limitations, interaction between different layers of government and, above all, transaction costs at play in real-world TDR. All of these factors are not implemented in our design, which necessarily reduces its scope. Nevertheless, investigating how a large number of individuals cope with the features of a TDR scheme can and should inform policy discussions and thus complement theoretical considerations and its natural limitations. Combining theoretical modelling and laboratory evidence might therefore be a valuable combination when discussing the introduction of TDR on a scientific and regulatory level.

Overall, we can point out a number of potential pitfalls to TDR schemes. While trading volumes and participation in the auctions are consistently high, participants show a tendency to value their initially acquired certificates higher than their current market value would suggest. We interpret this tendency as resulting from the well-known endowment effect, which precludes a fully efficient reallocation of certificates since it distorts prices by introducing a gap between bid and ask prices. In spite of this effect, prices tend to converge towards theoretical values over the course of the game; thus, there are strong learning effects in terms of pricing. We assume that those learning effects are very likely to occur within a real-world TDR scheme as well, thus reducing the allocative inefficiencies to be expected at the beginning. However, regulators should inform and train potential market participants in detail to avoid such inefficiencies after installing a cap and trade system. Thus, regulators should aim to realize learning effects prior to the introduction of this market based instrument. Optimally, overshooting prices and distortions in the allocation of certificates can be fully avoided. Further, communication structures already in place and interpersonal cooperation are likely to help in this process, which is an established finding in behavioral economics that also occurs in our TDR setting.

Nevertheless, despite these effects, the overshooting auction prices and the ensuing redistribution of income towards the auctioneer (most likely the federal government), will reduce market participants' (e.g., municipalities') political will to participate in a TDR scheme. Therefore, to keep these distortions from auctions manageable, our results can be interpreted in favor of grandfathering of certificates when compared to auctions. However, it might be advantageous to auction off some certificates to generate income to cover the costs of the administration of the cap and trade system. Another issue closely connected to the transfer of income manifests in budgetary issues. In our experiments, players have a common and fairly generous initial budget, which allows them to actively participate in the system and buy all certificates required for an efficient allocation, assuming fair prices. This design choice is unlikely to hold in a real-world setting where-at least in Germany-a substantial share of agents (municipalities) would have considerable budgetary constraints precluding them from buying the efficient amount of certificates or excluding them from the market at all. Contrastingly, some wealthy participants might dominate trading and exercise market power through excessive accumulation of certificates. This asymmetry in agent budgets renders the grandfathering process even more favorable as it enables smaller and less wealthy agents to conduct land-use projects at least by saving up free certificates. A system without grandfathering would lead to a polarization of development at the expense of less wealthy agents. This, again, would lead to substantial political opposition against the introduction of a TDR scheme, which could be countered by a politically influenced definition of a mechanism to grandfather certificates. Another solution might be seen in combining the auctioning of certificates with a compensation mechanism that favors financially less potent agents, where financial means are obtained by the income generated in the auctions. Then again, this compensation might be undertaken in a less interventional and more efficient way by the market 
when certificates are grandfathered in the first place. Also, the compensation through market forces is less prone to welfare damaging lobbying activities that might occur to boost compensation payments by the auctioneer and also leaves the auctioneer less powerful and market participants less dependent. Also, alternative auction designs might be less prone to overshooting prices than our uniform sealed bids auctions and should be investigated in future research.

Another issue to be addressed by policy-makers designing an actual TDR scheme is that political agents involved will show strong incentives to acquire certificates aiming to influence their political reputation, as illustrated by our experimental results. These incentives to conduct large-scale building projects are a constant feature to democratically elected governments potentially participating in TDR schemes and therefore need to be addressed by regulators. This might, for instance, be possible through installing specific time limits on the acquisition and use of certificates to prevent short-time reputation-based buying of certificates. Further, electoral periods can be designed not to overlap and augment the issue of excessive certificate prices, hindering an efficient certificate allocation. Although regulation might thus cope with this issue, the political incentives related to conducting building projects should be considered thoroughly to prevent detrimental effects.

A similar caveat applies to the issue of uncertainty with respect to projects revenues. While uncertainty tends to bring prices down closer to theoretical values, it also drives the allocation of certificates according to risk preferences, which can have substantially detrimental effects on overall welfare. Finding regulatory remedies for this issue might be difficult since uncertainties in project revenues are inherent in land consumption decisions. One might think of complementing insurance for failed building projects that stabilize certificate prices. Moreover, risky project revenues cause market participants to act more cautiously, which alleviates the issue of overshooting prices and might foster learning effects.

Apart from potential problems and their regulatory remedies, our findings principally show that TDR mechanisms work fairly efficiently in an empirical test with laboratory participants. The general structure is understood and markets reach overall very high levels of efficiency. While there are subtle behavioral biases, they do not pose a systematic issue to the overall stability and efficiency of the system. Grandfathering certificates avoids the unfavorable effects of certificate auctions. Overshooting prices are reduced quite quickly through learning effects; assuming communication and uncertainty, they should not be seen as a substantial issue. Exogenous shocks are compensated quite effectively without substantial negative effects on overall welfare. Collusion does not manifest in price distortions, while communication among participants has quite positive effects through knowledge spillover. Thus, the overarching message from the experimental tests of a TDR scheme is quite positive with a number of potential issues to be addressed by regulators and researchers alike.

From a research perspective, a number of aspects can and should be additionally tested in the laboratory to provide a broader empirical picture of TDR schemes. Mainly, the restrictions imposed in order to make our game understandable and practical to participants might be relaxed in specific domains to provide further evidence. The effects of transaction costs and market size might be the most relevant and interesting further research questions related to these aspects. The experiments could be extended in terms of duration, enabling more robust statements about market equilibria in the long run. Further, field experiments with municipal agents can and should be increased despite its practical difficulties, for example, based upon the results presented by [21]. Thus, more solid comparisons between students in the laboratory and the actual decision-makers could be obtained. Qualitative evidence could be used to determine the incentives and restrictions faced by actual decision-makers in the context of national systems of development rights, which could then be used to inform further experimental studies. Overall, our experimental framework can and should be seen as an initial outline, which can and should be complemented and improved by further studies.

Supplementary Materials: The following are available online at http:/ /www.mdpi.com/2071-1050/10/6/1972/ s1. All detailed information on the experimental procedures of the experiments reviewed above are explained in the respective papers; all supplementary information can be acquired from the authors upon request. 
Author Contributions: All authors contributed equally to this manuscript.

Funding: This research was funded by the German Environment Agency, grant number 3714111032.

Conflicts of Interest: The authors declare no conflict of interest.

\section{Appendix A}

Instructions for the Baseline treatment. All other instructions-German originals and English translations-are available from the authors upon request.

Overview of the Game

You can earn money in this game by realizing projects and trade with certificates. At the beginning, you will be randomly assigned to a group of 6 players, which will remain constant during the 15 periods of the game. All prices and values in the game will be paid in ECU with up to two positions after decimal point. $100 \mathrm{ECU}$ convert to $1 €$ for your payoff.

Projects

Overall, each player has 30 projects of Type A and 15 projects of Type B. Both types of projects have different values, which are shown in this table:

\begin{tabular}{cc}
\hline Type of Project & Project Value (in ECU) \\
\hline A & 0 to 100 \\
B & 10 \\
\hline
\end{tabular}

In each period, only one project can be realized. Before the game starts, the values of all Type A projects will be assigned and shown to you. All players are assigned different Type A projects.

\section{Certificates}

For the realization of Type A projects, you need 8 certificates each, Type B projects do not require certificates. Certificates are assigned to you at the beginning of each period and auctioned. Additionally, certificates can be traded among the players. In the game, you receive an endowment of $700 \mathrm{ECU}$ which you can use to buy certificates at the auction and from the other players. You can also sell certificates and thus increase your payoff.

Your Payoff

The payoffs you receive in the course of the game, as well as the sum of all realized projects add up to your final payoff. Further, a basic payoff of 400 ECU will be added.

\section{Course of the Game}

Each of the 15 periods follows an identical course, which consists of three phases.

\section{Phase 1: Allocation and Auctioning of Certificates}

At the beginning of each period, 12 certificates are allocated. The number of certificates a player receives is determined randomly at the beginning of the game and does not change during the game.

Additionally, after the allocation, 12 certificates are auctioned. Depending on your current funds, you can bid for a number of certificates of your choosing at a unitary price. The 12 highest bids will receive the certificates to the price of the lowest successful bid.

\section{Phase 2: Trading of Certificates}

Following the allocation and auctioning, this phase lets you trade with the other five players, i.e., buy and sell certificates. You can offer a trade yourself and also accept offers from other players. To clarify this, you see the respective screen of the trading phase below: 


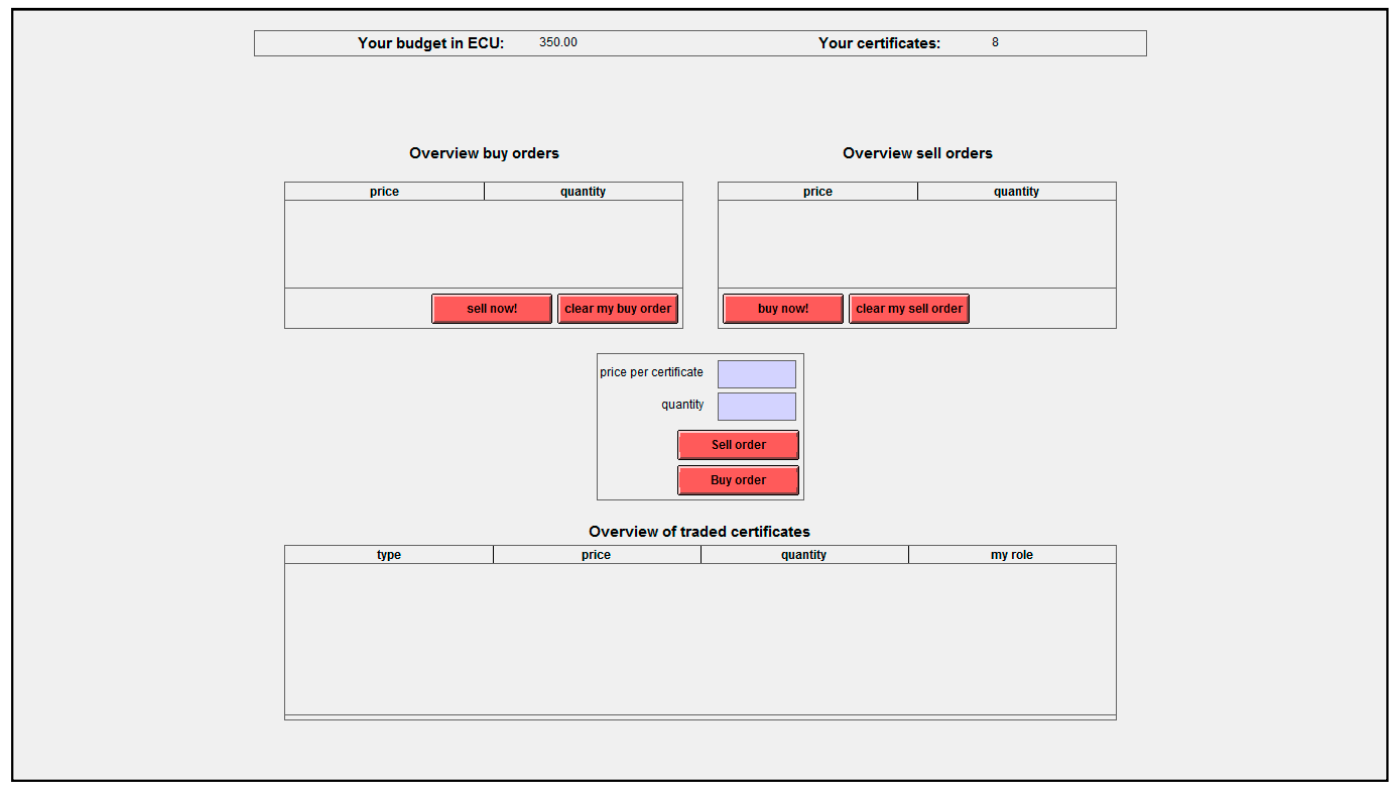

\section{Offering a Trade}

In the lower box, you can enter a price (in ECU) and the respective amount of certificates that you would like to buy.

- By clicking "Buy order", all players are shown your buying desire in the left box. Once another player agrees to your offer, you will receive the respective number of certificates. The total value (price $x$ quantity) of the trade will be withdrawn from your funds.

- By clicking "Sell order", all players are shown your sell offer in the box on the right. Once another player accepts your offer, you sell the respective number of certificates. The total value (price $\times$ quantity) of the trade will be added to your funds.

\section{Accepting Another Player's Offer}

In the boxes on the right and left side, you can see all current buy and sell offers for certificates. If you choose an offer and click on "sell now!" or "buy now!", you make the trade with the respective player.

You are allowed to trade as often as you please. You can also make multiple sell and buy offers at the same time. The trading phase ends automatically once 2 min have passed.

\section{Phase 3: Realizing Projects}

In the third phase of the game, you can realize one of your projects. You will receive the respective payoffs (project value in ECU) at the end of the game. After the third phase, the next period begins. Certificates that are not used in one period can be saved for subsequent periods. Note, however, that you will not receive a payoff for certificates that remain unused until the end of period 15 !

\section{References}

1. Nuissl, H.; Schroeter-Schlaack, C. On the economic approach to the containment of land consumption. Environ. Sci. Policy 2009, 12, 270-280. [CrossRef]

2. Thorsnes, P.; Simons, G.P. Letting the market preserve land: The case for a market-driven transfer of development rights program. Contemp. Econ. Policy 1999, 17, 256-266. [CrossRef]

3. Van der Veen, M.; Spaans, M.; Janssen-Jansen, L. Using compensation instruments as a vehicle to improve spatial planning: Challenges and opportunities. Land Use Policy 2010, 27, 1010-1017. [CrossRef] 
4. Vejchodskáa, E. Tradable planning permits versus auctioned tradable development rights: Different trading agents, different policy outcomes. J. Environ. Plan. Manag. 2015, 59, 1418-1437. [CrossRef]

5. Ward, P. On the use of tradable development rights for reducing flood risk. Land Use Policy 2013, 31, 576-583. [CrossRef]

6. Chan, E.H.W.; Hou, J. Developing a framework to appraise the critical success factors of transfer development rights (TDRs) for built heritage conservation. Habitat Int. 2015, 46, 35-43. [CrossRef]

7. Colavitti, A.M.; Serra, S. The transfer of development rights as a tool for the urban growth containment: A comparison between the United States and Italy. Pap. Reg. Sci. 2017. [CrossRef]

8. Kaplowitz, M.D.; Machemer, P.; Pruetz, R. Planners' experiences in managing growth using transferable development rights (TDR) in the United States. Land Use Policy 2008, 25, 378-387. [CrossRef]

9. Linkous, E.R. Transfer of development rights in theory and practice: The restructuring of TDR to incentivize development. Land Use Policy 2016, 51, 162-171. [CrossRef]

10. Linkous, E.R. Transfer of development rights and urban land markets. Environ. Plan. A Econ. Space 2017, 49, 1122-1145. [CrossRef]

11. Pruetz, R.; Standridge, N. What makes transfer of development rights work? Success factors from research and practice. J. Am. Plan. Assoc. 2009, 75, 78-87. [CrossRef]

12. Tan, R.; Beckmann, V. Diversity of practical quota systems for farmland preservation: A multicountry comparison and analysis. Environ. Plan. C Politics Space 2010, 28, 211-224. [CrossRef]

13. Greenstone, M.; Gayer, T. Quasi-experimental and experimental approaches to environmental economics. J. Environ. Econ. Manag. 2009, 57, 21-44. [CrossRef]

14. Meub, L.; Proeger, T.; Bizer, K.; Henger, R. Die Effizienz von Zuteilungsmechanismen bei Flächenzertifikaten zwischen Versteigerung und Grandfathering_Experimentelle Evidenz. Zeitschrift für Wirtschaftspolitik 2017, 66, 80-109. [CrossRef]

15. Meub, L.; Proeger, T.; Bizer, K.; Henger, R. The political economy of certificates for land use in Germany-Experimental evidence. J. Environ. Policy Plan. 2017, 19, 712-732. [CrossRef]

16. Meub, L.; Proeger, T.; Bizer, K.; Henger, R. Experimental evidence on the resilience of a cap \& trade system for land use in Germany. Land Use Policy 2016, 51, 95-108. [CrossRef]

17. Proeger, T.; Meub, L.; Bizer, K. The role of communication on an experimental market for tradable development rights. Land Use Policy 2017, 68, 614-624. [CrossRef]

18. Proeger, T.; Meub, L.; Bizer, K. Tradable development rights under uncertainty: An experimental approach. J. Environ. Econ. Policy 2018. forthcoming. [CrossRef]

19. Convery, F.J. Reflections-The emerging literature on emissions trading in Europe. Rev. Environ. Econ. Policy 2009, 3, 121-137. [CrossRef]

20. Grimm, V.; Ilieva, L. An experiment on emissions trading: The effect of different allocation mechanisms. J. Regul. Econ. 2013, 44, 308-338. [CrossRef]

21. Henger, R. Tradable Planning Permits to Control Land Development in Germany: A Laboratory Testbed Experiment. J. Environ. Policy Plan. 2013, 15, 843-852. [CrossRef]

22. Falk, A.; Fehr, E. Why labour market experiments? Labour Econ. 2003, 10, 399-406. [CrossRef]

23. Falk, A.; Heckman, J.J. Lab experiments are a major source of knowledge in the social sciences. Science 2009, 326, 535-538. [CrossRef] [PubMed]

24. Madrian, B.C. Applying Insights from Behavioral Economics to Policy Design; National Bureau of Economic Research Working Paper No. w20318; National Bureau of Economic Research: Cambridge, MA, USA, 2014.

25. Chetty, R. Behavioral economics and public policy: A pragmatic perspective. Am. Econ. Rev. 2015, 105, 1-33. [CrossRef]

26. Harrison, G.W.; List, J.A. Field experiments. J. Econ. Lit. 2004, 42, 1009-1055. [CrossRef]

27. Charness, G.; Fehr, E. From the lab to the real world. Laboratory experiments provide precise quantitative predictions of peer effects in the field. Science 2015, 350, 512-513. [CrossRef] [PubMed]

28. Santos, A.C. Behavioural and experimental economics: Are they really transforming economics? Camb. J. Econ. 2011, 35, 705-728. [CrossRef]

29. Beckmann, V.; Padmanabhan, M. Analysing institutions: What method to apply? In Institutions and Sustainability; Beckmann, V., Padmanabhan, M., Eds.; Springer: Dordrecht, The Netherlands, 2009; pp. 341-371. 
30. Joskow, P.L.; Schmalensee, R.; Bailey, E.M. The Market for Sulfur Dioxide Emissions. Am. Econ. Rev. 1998, 88, 669-685.

31. Ellerman, A.D.; Buchner, B.K. The European Union Emissions Trading Scheme: Origins, Allocation, and Early Results. Rev. Environ. Econ. Policy 2007, 1, 66-87. [CrossRef]

32. Wrake, M.; Burtraw, D.; Löfgren, A.; Zetterberg, L. What have we learnt from the European Union's emissions trading system? Ambio 2012, 41, 12-22. [CrossRef] [PubMed]

33. Rinaudo, J.-D.; Calatrava, J.; De Byans, M.V. Tradable water saving certificates to improve urban water use efficiency: An ex-ante evaluation in a French case study. Aust. J. Agric. Resour. Econ. 2016, 60, 422-441. [CrossRef]

34. De Vries, F.P.; Hanley, N. Incentive-Based Policy Design for Pollution Control and Biodiversity Conservation: A Review. Environ. Resour. Econ. 2016, 63, 687-702. [CrossRef]

35. Zaeske, A.L.; Krishnamurthy, C.K. Managing Water: Rights, Markets, and Welfare; CERE Working Paper 2017-2; Centre for Environmental and Resource Economics: Umeå, Sweden, 2017. [CrossRef]

36. Harman, B.; Choy, D.L. Perspectives on tradable development rights for ecosystem service protection: Lessons from an Australian peri-urban region. J. Environ. Plan. Manag. 2011, 54, 617-635. [CrossRef]

37. Wang, H.; Tao, R.; Tong, J. Trading land development rights under a planned land use system: The "Zhejiang Model". China World Econ. 2009, 17, 66-82. [CrossRef]

38. Henger, R.; Bizer, K. Tradable planning permits for land-use control in Germany. Land Use Policy 2010, 27, 843-852. [CrossRef]

39. Micelli, E. Development rights markets to manage urban plans in Italy. Urban Stud. 2002, 39, 141-154. [CrossRef]

40. Janssen-Jansen, L.B. Space for Space, a transferable development rights initiative for changing the Dutch landscape. Landsc. Urban Plan. 2008, 87, 192-200. [CrossRef]

41. Menghini, G.; Gemperle, F.; Seidl, I.; Axhausen, K.W. Results of an agent-based market simulation for transferable development rights (TDR) in Switzerland. Environ. Plan. B Plan. Des. 2015, 42, 157-183. [CrossRef]

42. Pruetz, R. Saved by Development: Preserving Environmental Areas, Farmland and Historic Landmarks with Transfer of Development Rights; Arje Press: Burbank, CA, USA, 1997.

43. German Federal Government (Bundesregierung). Perspektiven für Deutschland: Unsere Strategie für eine Nachhaltige Entwicklung; Presse- und Informationsamt der Bundesregierung: Berlin, Germany, 2002.

44. German Coalition Treaty. 2013. Available online: https://www.bundesregierung.de/Content/DE/ _Anlagen/2013/2013-12-17-koalitionsvertrag.pdf;jsessionid=277BAF8EC8B6A64CF05EA1441DB8FE00. s6t1?_blob=publicationFile\&v=3 (accessed on 17 May 2018).

45. German Federal Statistical Office (Statistisches Bundesamt). Siedlungs- und Verkehrsfläche wächst um 81 Hektar. Pressemitteilung 23/13 vom 17. January 2013. Available online: https://www.destatis.de/ DE/PresseService/Presse/Pressemitteilungen/2013/01/PD13_023_331pdf.pdf?_blob=publicationFile (accessed on 17 May 2018).

46. Henger, R. Tradable Planning Permits-Fiscal Incentives for Developing Land and the Regulation of Open Space with a Cap-and-Trade System in Germany. Ph.D. Dissertation, Universität Göttingen, Göttingen, Germany, 2010.

47. Davy, B. Flächenhaushalt reconsidered: Alternatives to the German Federal 30 hectares goal. In Regional Planning for Open Space; van der Valk, A., van Dijk, T., Eds.; Routledge: London, UK, 2009; pp. 279-300.

48. Fischer, B.; Klauer, B.; Schiller, J. Prospects for sustainable land-use policy in Germany: Experimenting with a sustainability heuristic. Ecol. Econ. 2013, 95, 213-220. [CrossRef]

49. Santos, R.; Schroeter-Schlaack, C.; Antunes, P.; Ring, I.; Clemente, P. Reviewing the role of habitat banking and tradable development rights in the conservation policy mix. Environ. Conserv. 2015, 42, 294-305. [CrossRef]

50. Harman, B.; Pruetz, R.; Houston, P. Tradeable development rights to protect peri-urban areas: Lessons from the United States and observations on Australian practice. J. Environ. Plan. Manag. 2015, 58, 357-381. [CrossRef]

51. Machemer, P.L.; Kaplowitz, M.D. A framework for evaluating transferable development rights programmes. J. Environ. Plan. Manag. 2002, 45, 773-795. [CrossRef]

52. Danner, J.C. TDRs-great idea but questionable value. Apprais. J. 1997, 65, 133-142. 
53. Kopits, E.; McConnell, V.; Walls, M. Making markets for development rights work: What determines demand? Land Econ. 2008, 84, 1-16. [CrossRef]

54. Lynch, L.; Musser, W.N. A relative efficiency analysis of farmland preservation programs. Land Econ. 2001, 77, 577-594. [CrossRef]

55. Lynch, L.; Lovell, S.J. Combining spatial and survey data to explain participation in agricultural land reservation programs. Land Econ. 2003, 79, 259-276. [CrossRef]

56. Fischbacher, U. z-Tree: Zurich toolbox for ready-made economic experiments. Exp. Econ. 2007, 10, 171-178. [CrossRef]

57. Greiner, B. An online recruiting system for economic experiments. In Forschung und wissenschaftliches Rechnen; Kremer, K., Macho, V., Eds.; GWDG Bericht 63: Göttingen, Germany, 2004; pp. 79-93.

2018 by the authors. Licensee MDPI, Basel, Switzerland. This article is an open access article distributed under the terms and conditions of the Creative Commons Attribution (CC BY) license (http:/ / creativecommons.org/licenses/by/4.0/). 